\title{
BIOMIMICRY IN ENGINEERING EDUCATION
}

Miller, J D

Speaker's Bureau of the Biomimicry Guild \& Department of Environmental Engineering, University of Guelph, Ontario, Canada jamiemill@gmail.com

\section{INTRODUCTION}

The discourse on reforming engineering education regularly suggests that engineering curricula should include multidisciplinary course work and a strong focus on environmental sustainability ${ }^{1}$.

The science of biomimicry ensures both. By creatively converging technology and the natural world, biomimicry requires a collaboration of engineers and biologists and uses a design methodology that is founded on principles of environmental sustainability.

\section{BIOMIMICRY DEFINED}

Biomimicry is an emerging design ethic that consciously observes and emulates nature's forms, processes and systems ${ }^{2}$. It is based on the understanding that for four billion years organisms in nature have been evolving and refining solutions to universal problems, e.g. packaging, adhesion, climate control, benign manufacturing, etc. They achieve these feats within the same context and boundary conditions as humans. Biomimicry is a tool that encourages engineers to consciously emulate these blueprints and recipes to find ways to improve their innovations. It is studying trees to create pumps, or electric eels to produce electricity. It is asking a leaf for design advice for solar voltaics, or the mangrove for guidance on desalination.

Using nature to inspire engineering design is not a new idea; think of Buckminster Fuller, Leonardo DaVinci, Antoni Gaudi, and First Nations People, ${ }^{2}$. But Janine Benyus - author of Biomimicry: Innovation Inspired by Nature and co-founder of the biomimicry consulting company Biomimicry Guild - has established biomimicry to incorporate biologically-inspired design at all phases: ideation, creation and evaluation. In nature, organisms create, manage and process their technologies while enhancing their surrounding habitat and contributing to the continuity of life ${ }^{2}$. Biomimicry uses nature's best ideas as a model, measure and mentor to create sustainable designs and begin to more sustainably converge our way of doings things with the natural world.

\section{NATURE AS MODEL}

Biomimicry models nature at three levels: form, process and system ${ }^{2}$.

Emulating natural form is the most common and simple approach to using nature as a model. It focuses on the physical characteristics of natural designs, such as copying the hooks of burdock burrs to make Velcro, or creating wind turbine blades that mimic the shape of a humpback whale's fins. At this level, engineers simply utilize the billion years of evolved efficiencies of nature's physical designs. For example, Dr. Frank Fish found that emulating a humpback whale fin could significantly increase lift and decrease drag in a wind turbine blade ${ }^{4}$. However, just copying form may or may not support sustainability on a systematic level.

The Mercedes-Benz bionic car for example, emulated the shape of a boxfish and the framework of bones to drastically improve automotive aerodynamics and fuel consumption without reducing strength or safety, (drag coefficient of 0.19 and $84 \mathrm{mpg}$ at constant $56 \mathrm{mph}$ ). This "shallow" approach however, still required the use of materials and processes that negatively impact the environment, e.g. fossil fuels.

For our designs to become more fully life-inspired, biomimicry motivates engineers to also emulate natural processes, i.e. how things are made. To process spider silk for example, a spider uses a simple set of common raw materials that are processed at body temperature and pressure, without toxins and in water ${ }^{2,6}$. This is true green chemistry and the second level of biomimicry.

The deepest level of biomimicry is to mimic natural ecosystems, i.e. the way things fit in. The intent at this level is to create products and processes that fit seamlessly within the larger system and work to restore, rather than deplete the earth. In this phase, engineers learn to observe nature as a measure for the appropriateness of their designs.

\section{NATURE AS MEASURE}

Biomimicry is a unique design tool because it avoids trial and error metrics for determining how well a technology will adapt or interfere with nature. Instead, it uses a set of principles, strategies and laws that commonly exist in nature as a template for template for design ${ }^{6}$.
By knowing the common strategies that nature uses, engineers can incorporate those into their designs and design process in order to more effectively integrate their technology into the natural world.

Examples of some of the identified principles are: nature adapts and evolves by being resourceful and opportunistic (using shape rather than material, using simple and common building materials and free energy); life creates conditions conducive to life by optimizing rather than maximizing their designs (multi-functional designs, fitting form to function, recycling all materials); using benign manufacturing (lifefriendly materials, water based chemistry, self-assembly $)^{2,6}$.

\section{NATURE AS MENTOR}

Biomimicry is not just a design methodology but also a paradigm of sustainability ${ }^{2}$. Its main focus is on finding a balance between our natural and constructed environments.

It is a science that unites biologists, ecologists, designers, and engineers in a collaborative effort to make efficient and long-lasting designs.

It not only unites technology and biology, but also economics, industry and environmentalism. Biomimicry works with what we have now - that is, the technologies and ways of doing things that currently persist. Increasing efficiencies and optimizing design forms and processes can decrease operating costs. Consider Japan's Bullet Train, which emulated the shape of the King Fisher to help reduce electricity usage by 10 percent while increasing speed by 15 percent $^{7}$. With biomimicry, engineers can evolve existing technologies to become cost effective, more efficient and more sustainable.

However, there is a great deal of research required to fully utilize nature's design strategies. Of the estimated 30 million species on this planet, we have only identified 1.4 million, or 4.7 percent $^{2}$. We know and understand very little of all the life on the biosphere. In using biomimicry as a design tool, it is important that we consciously choose nature's best ideas to emulate because there may be things in nature that we do not understand and that that may not seem appropriate for mimicking. Biomimicry is about finding organisms that have adapted solutions that work, that last and that are appropriate.

The most important idea of biomimicry is that it can inspire creativity and hope ${ }^{2}$. Making a fabric with the strength to weight ratio of spider silk without the use of toxic chemicals is a difficult task. But biomimicry is about using the steps of emulating form, process and system in nature to guide engineering designs to become more efficient and more fully integrated with nature. It is a design method that allows engineers to observe nature and amaze at the competency and capabilities of our planet. Through this, engineers may also find a respect for nature, and in turn a desire to protect it.

\section{REFERENCES}

1. Miller JD, Humanitarian Engineering: Addressing the Global Influence of Applied Technology, in Engineering Education [thesis]. Kingston, Ontario : Queen's University ; 2008

2. Benyus JM, Biomimicry: Innovation Inspired by Nature, New York: William Morrow and Company, Inc., 1997

3. Vincent JF, Biomimetics-its practice and theory. Journal of the Royal Society Interface. 2006; 3(9): 471-482

4. Weber P, Howle L, Murray M, Fish F, Lift and drag performance of odontocete cetacean flippers. Experimental Biology. 2009; 212: 21492158

5. Phenix M. Fish-Inspired Car: Mercedes's Bionic concept takes smallcar thinking to new depths. Popular Science.

http://www.popsci.com/aerodynamic/article/2005-08/fish-inspired-car. Accessed May 14, 2010.

6. Hoagland M, Dodson B, Hauck J. Exploring the Way Life Works: The Science of Biology. Jones and Bartlett Publishers, 2001.

7. The Biomimicry Institute. http://www.biomimicryinstitute.org/casestudies/case-studies/transportation.html. Accessed May 14, 2010 McMaster DS, Robson MA. Science 1992;17:66-73. 